\title{
Case Studies of Damage to Tall Steel Moment-Frame Buildings in Southern California during Large San Andreas Earthquakes
}

\author{
by Swaminathan Krishnan, Chen Ji,* Dimitri Komatitsch, and Jeroen Tromp
}

\begin{abstract}
On 9 January 1857, a large earthquake of magnitude 7.9 occurred on the San Andreas fault, with rupture initiating at Parkfield in central California and propagating in a southeasterly direction over a distance of more than $360 \mathrm{~km}$. Such a unilateral rupture produces significant directivity toward the San Fernando and Los Angeles basins. Indeed, newspaper reports of sloshing observed in the Los Angeles river point to long-duration (1-2 $\mathrm{min})$ and long-period $(2-8 \mathrm{sec})$ shaking. If such an earthquake were to happen today, it could impose significant seismic demand on present-day tall buildings. Using state-of-the-art computational tools in seismology and structural engineering, validated using data from the 17 January 1994, magnitude 6.7 Northridge earthquake, we determine the damage to an existing and a new 18story steel moment-frame building in southern California due to ground motion from two hypothetical magnitude 7.9 earthquakes on the San Andreas fault. Our study indicates that serious damage occurs in these buildings at many locations in the region in one of the two scenarios. For a north-to-south rupture scenario, the peak velocity is of the order of $1 \mathrm{~m} \cdot \mathrm{sec}^{-1}$ in the Los Angeles basin, including downtown Los Angeles, and $2 \mathrm{~m} \cdot \mathrm{sec}^{-1}$ in the San Fernando valley, while the peak displacements are of the order of $1 \mathrm{~m}$ and $2 \mathrm{~m}$ in the Los Angeles basin and San Fernando valley, respectively. For a south-to-north rupture scenario the peak velocities and displacements are reduced by a factor of roughly 2 .
\end{abstract}

Introduction

The risk of earthquakes in southern California arises from two sources: well-mapped-out faults such as the San Andreas, Newport-Inglewood, and Santa Monica-Hollywood-Raymond faults that have some form of surface expression, and the network of blind-thrust faults hidden deep inside the Earth that includes the Northridge fault and the Puente Hills fault underneath downtown Los Angeles. While the San Andreas strike-slip fault system has the potential for large (moment magnitude $\sim 8$ ) earthquakes, typically every 200-300 years (Sieh, 1977, 1978a), the blind-thrust faults have the potential for more moderate magnitude $\sim 7$ earthquakes (Shaw and Suppe 1996). Fortunately, in modern history the urban areas of southern California have thus far been spared from the strongest shaking generated by large strikeslip earthquakes. The magnitude 6.7 earthquake of 17 January 1994, on the Northridge blind-thrust fault, however, caused 57 deaths and economic losses in excess of $\$ 40$ billion (Eguchi et al., 1998; Petak and Elahi, 2000). This earthquake exposed the vulnerability of steel moment-resisting frame buildings to fracture (SAC, 1995a, b, c). These build-

*Present address: Department of Geological Sciences, University of California, Santa Barbara, California 93106. ings resist lateral forces from an earthquake through bending in rigidly connected (welded) beams and columns. Because of certain construction practices and the use of nonductile weld material, however, a significant number of connections fractured in some of these buildings. Many of the momentframe buildings in southern California were constructed before 1976 (EQE International, Inc., 1995), when the understanding of the nature and power of earthquake forces and their effects on buildings was inadequate. Therefore the question arises as to what would happen to the many tall steel buildings in the Los Angeles and San Fernando basins if a large earthquake were to occur on the San Andreas fault. Can we estimate damage and consequent losses in these buildings? There have been many improvements in building codes and construction practices since 1994, and buildings designed according to the latest code (1997 Uniform Building Code, UBC97, ICBO, 1997), termed "new/redesigned buildings" in this article, are expected to perform far better than existing buildings, defined as those designed using codes preceding the UBC97, in large earthquakes. Will they, in fact, perform better and, if so, is this performance adequate? Before we can answer these questions, we need to be able to answer more fundamental questions, for example, 
what kind of shaking would be experienced in this region during such an earthquake? What would the frequency content of the shaking be? What about the amplitude and duration of significant shaking? We have a qualitative feel for the extent and intensity of ground shaking from newspaper reports (Agnew and Sieh, 1978; Meltzner and Wald, 1998) following the magnitude 7.9 earthquake of 9 January 1857 on the San Andreas fault. However, we need estimates of the ground-motion waveforms for performing quantitative seismic-hazard assessment in a rigorous manner.

In this study we combine state-of-the-art computational tools in seismology and structural engineering to perform a 3D simulation of the rupture of a $290-\mathrm{km}$ section of the San Andreas fault, the generation and propagation of the resulting seismic waves, the subsequent ground shaking in the Los Angeles and San Fernando basins, and the resulting damage to two 18-story steel moment-frame buildings in the region. Each of these parts requires simulation at very different temporal and spatial scales that are best performed using taskspecific software. Seismic-wave propagation can be modeled in a linear viscoelastic manner, whereas building damage has to be modeled in a nonlinear fashion. A decade ago, Heaton and colleagues (Heaton et al., 1995; Hall et al., 1995; Hall, 1998) simulated the near-source ground motions of a magnitude 7.0 thrust earthquake on a spatial grid of $60 \mathrm{~km}$ by $60 \mathrm{~km}$ using a vertically stratified crustal model that approximates the rock properties in the Los Angeles basin, and then modeled the response of a 20 -story steel-frame building and a three-story base-isolated building. Olsen et al. (1995) and Graves (1998) simulated seismic-wave propagation generated by a magnitude 7.75 earthquake on a different section of the San Andreas fault. Here we integrate many aspects of the earthquake-structure problem including the finite-source model of a real earthquake (Ji et al., 2002, 2003), seismicwave propagation in a 3D Earth model (Komatitsch and Tromp, 1999; Komatitsch et al., 2004; Liu et al., 2004), and 3D nonlinear damage analyses of buildings using threecomponent ground-motion waveforms (Carlson, 1999; Krishnan, 2003a), validating these procedures using real data from a recent earthquake.

\section{Model Domain and Building Characteristics}

The seismological domain of our analysis includes all of southern California and extends north into the central valley beyond Parkfield, but we restricted the engineering analysis to the main sedimentary basins of San Fernando, Los Angeles, and San Gabriel (Fig. 1). For the scenarios considered in this study, ground motions south of Irvine going toward San Diego are unlikely to be strong enough to warrant a detailed engineering analysis. The solid circles in the figure denote some of the major cities in the region. We have divided the region using a grid spaced at $1 / 32$ of a degree (i.e., about $3.5 \mathrm{~km}$ ) each way, with a total of 636 analysis sites. Also shown in the figure is the surface projection of the Northridge fault that ruptured during the 17 January 1994 earthquake. The inset illustrates the region of interest in relation to the San Andreas fault rupture scenarios under consideration.

Many types of buildings in southern California are at risk of sustaining damage during strong ground shaking from a large earthquake on the San Andreas fault. These include the numerous nonductile concrete buildings and unreinforced masonry buildings spread across Los Angeles. At the same time, the large-amplitude long-period, longduration seismic waves that can be expected from a large San Andreas earthquake can excite the dominant long-period modes of tall buildings, especially those in the midheight, 15-30 story, range. Having said this, no detailed analyses have been performed to confirm the safety of high-rise buildings 40 stories and taller during either large distant earthquakes or moderate near-source earthquakes that could generate large displacement pulses at great velocities. It is generally assumed that these buildings, usually with dual structural systems offering greater redundancy or with tubular structural systems that can counter strong wind forces, will be able to resist shaking from a distant earthquake fairly well. Within the 15-30-story class there are more steel buildings than reinforced concrete ones; for example, in 1993, there were 190 steel buildings above 8 stories compared with 121 concrete buildings (EQE, 1995) in the Los Angeles and Ventura Counties; for buildings in the midheight range this ratio is likely to have been more skewed toward steel. This is a prototype study, and in such an analysis it is important to target buildings that have already been investigated in detail, and whose behavior is well understood, so that a proof of concept can be established. Steel moment-frame buildings have been studied extensively since the Northridge earthquake (SAC, 1995a, b; Carlson, 1999; Krishnan, 2003b). Based on these considerations, we have chosen 18-story steel moment-frame buildings as the focus of this study. In particular, we have selected two buildings (Fig. 2). The base building is an existing 18-story steel moment-frame building located on Canoga Avenue in Woodland Hills that suffered significant damage (moment-frame connection fractures) during the 1994 Northridge earthquake. This building has been the subject of detailed study by many research groups since the Northridge earthquake (SAC, 1995b). The second building is similar to the base building, but the structural system (lateral force-resisting system) has been redesigned according to the current building code, UBC97 (ICBO, 1997). The 1997 code regulations specify larger design forces (to account for near-source effects) and call for greater redundancy in the lateral force-resisting system. This results in a greater number of bays of moment frames (a single bay of a one-story moment frame consists of an assembly of two columns and a single beam spanning from column to column; for a 20-story building this assemblage would be replicated for each story, one on top of the other). As a result, the dynamic properties of the two buildings are significantly different. In general, the redesigned building can be expected to perform better than the existing building in the event of 


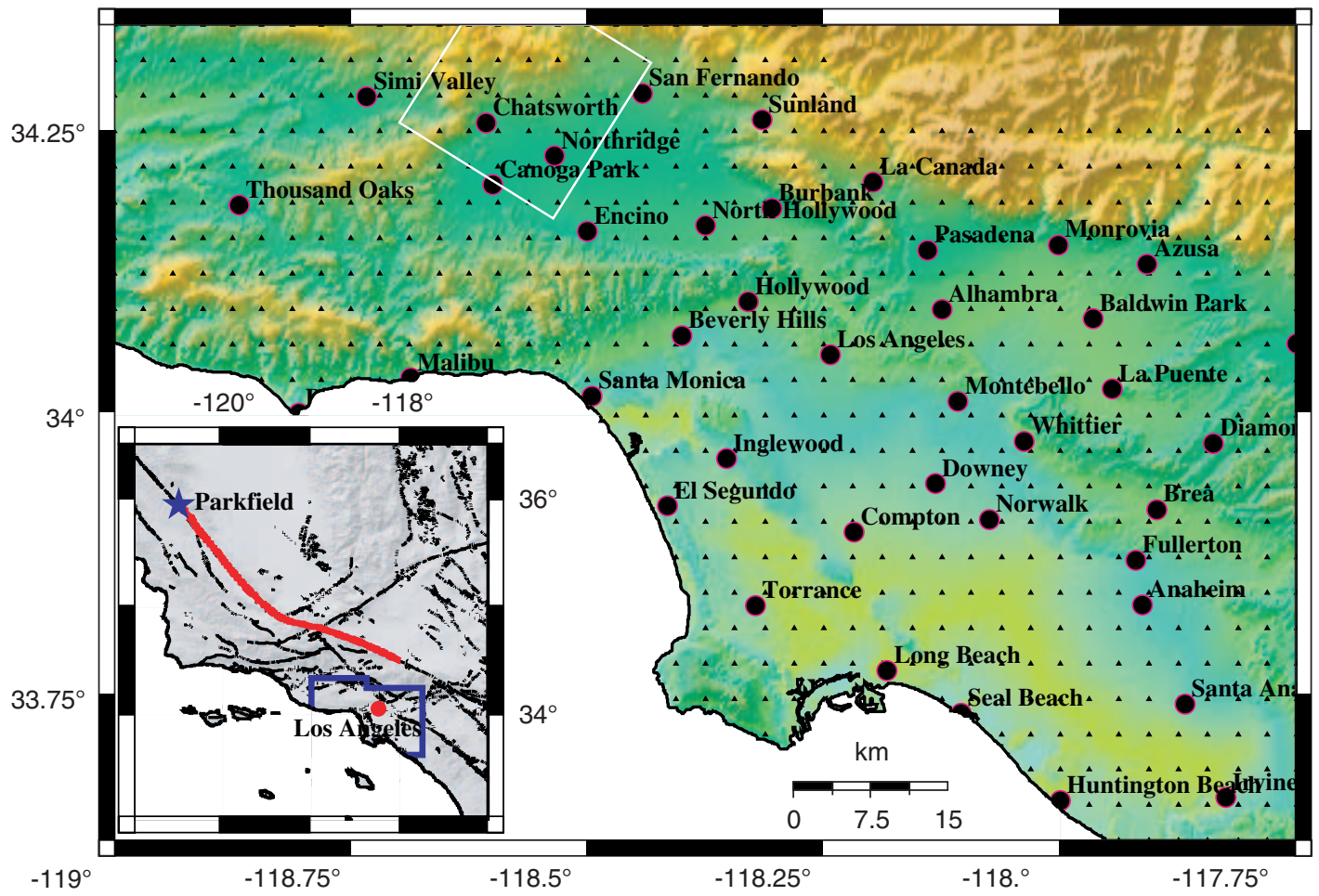

Figure 1. Geographical scope of the simulation. The color scheme reflects topography, with green denoting low elevation and yellow denoting mountains. The filled triangles represent the 636 sites at which seismograms are computed and buildings are analyzed. The white box is the surface projection of the Northridge fault. The red line in the inset is the surface trace of the hypothetical 290-km rupture of the San Andreas fault that is the primary focus of this study. The area enclosed by the blue polygon denotes the region covered by the 636 sites.

an earthquake. The description of the two buildings, the design methodology for the new building, and the detailed comparison of the two buildings in terms of dynamic properties, static strength, and ductility, have been presented in an online report (Krishnan et al., 2005).

\section{Numerical Simulation of Ground Motion}

The two techniques adopted by seismologists to simulate ground motion consist of either a deterministic or an empirical approach. In the deterministic approach, the elastic wave equation is solved numerically in a realistic 3D Earth model and the ground motion is directly computed without any additional assumptions. In the case of the Los Angeles basin, the accuracy and frequency limitations depend on the quality of the 3D Los Angeles basin model, which has improved steadily during the past decade, and on the numerical resolution of the 3D seismic wave propagation simulation. For our study, we have used one of the two well-accepted 3D southern California Earth models, the Harvard-LA model (Suss and Shaw, 2003), the other being the SCEC Community Velocity Model (Magistrale et al., 1996, 2000; Kohler et al., 2003). Both models allow us to model the basin response down to a shortest period of approximately $2 \mathrm{sec}$
(Komatitsch et al., 2004). The Harvard-LA sedimentary basin model (which includes the crust and the upper mantle) is constrained by hundreds of petroleum industry well logs and more than $20,000 \mathrm{~km}$ of seismic-reflection profiles. A limitation of both Earth models is that the top soil layer, also called the geotechnical layer, is not included because of lack of sufficient data and the numerical complexity associated with low shear-wave speeds in this layer, which would require a very dense numerical grid to ensure correct sampling of the corresponding seismic wavelengths. This typically softer layer may have the effect of amplifying the ground motion (Haskell, 1960; Anderson et al., 1996). Having said this, the buildings that we analyze are long-period structures most affected by long-period waves with wavelengths far greater than the depth of the unmodeled soil layer; these waves simply do not see the layer, and as a result, the effect of the top soil layer on the simulated ground motion (with periods longer than $2 \mathrm{sec}$ ) is likely to be insignificant. Furthermore, maps of the geotechnical layer do not currently exist for southern California. A final limitation is that 3D seismic-wave propagation codes that can handle a geotechnical layer are currently not available. Including the geotechnical layer, when a model becomes available, will require the consideration of very high frequencies and much 
(a)

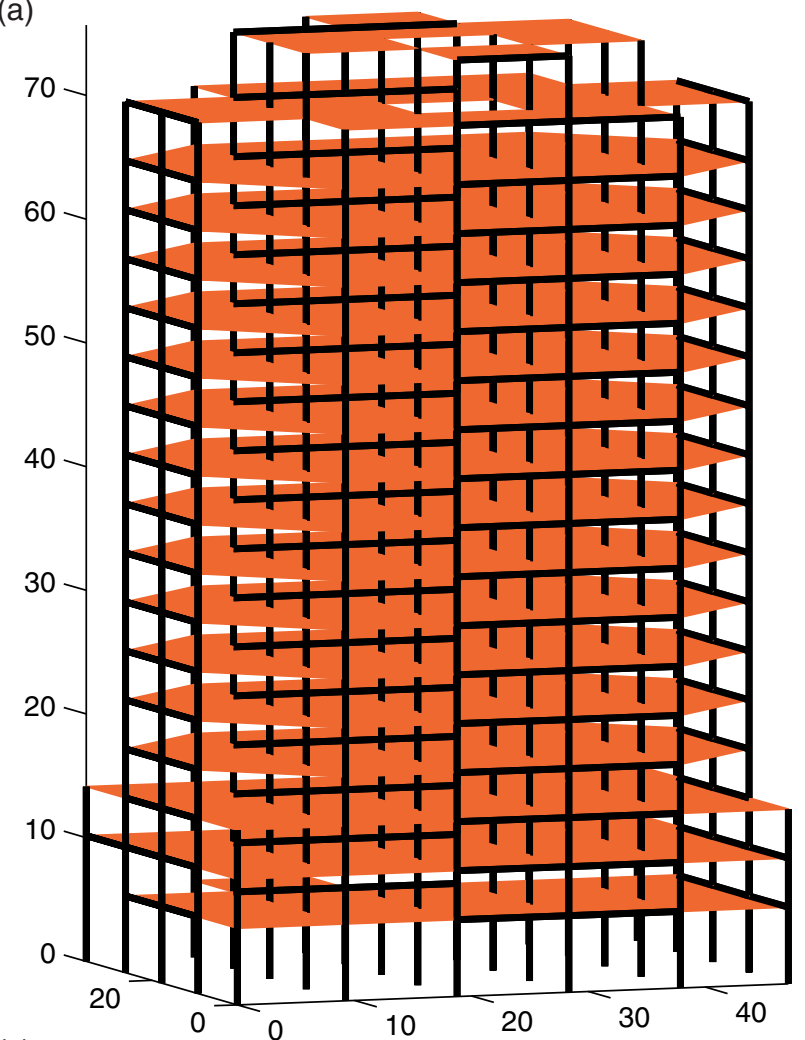

(c)

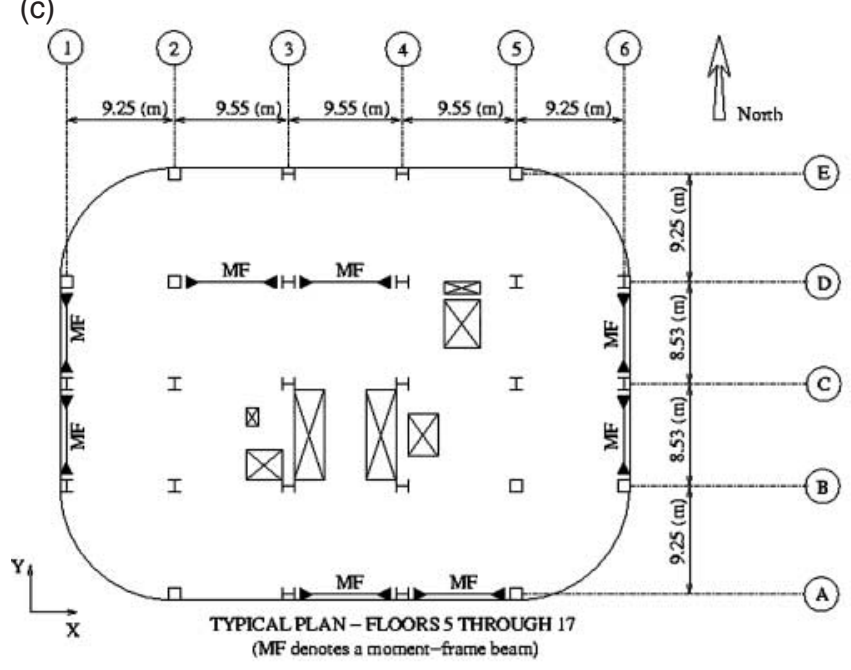

(b)

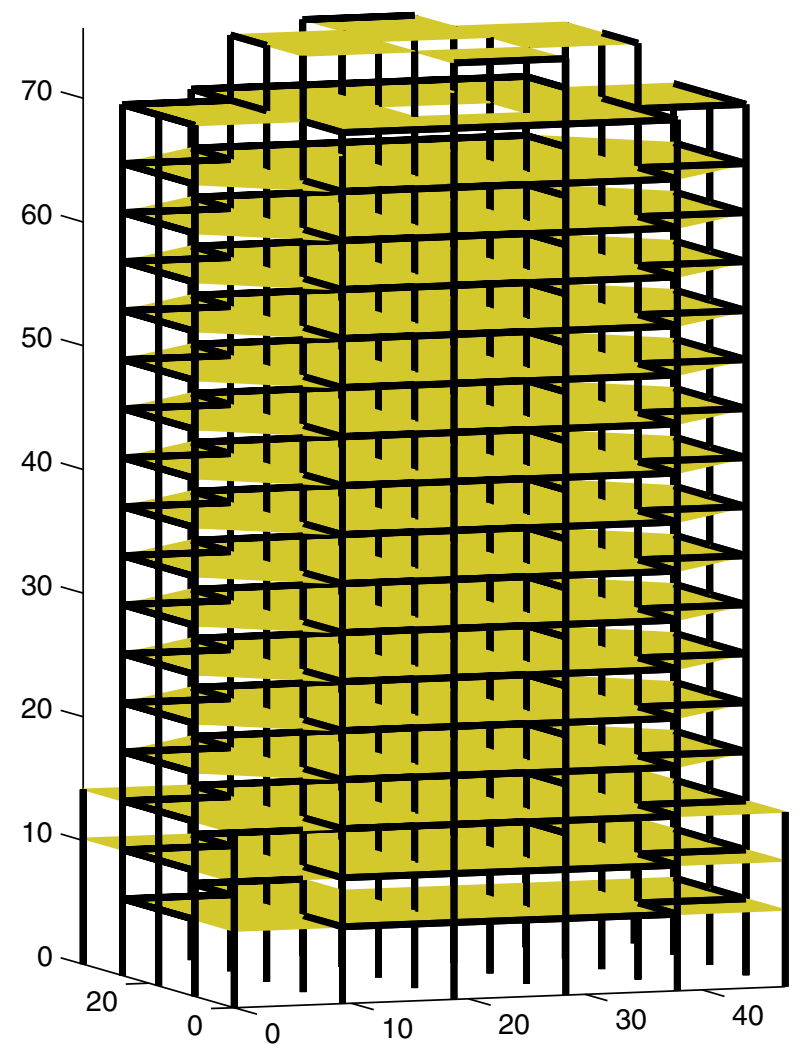

(d)

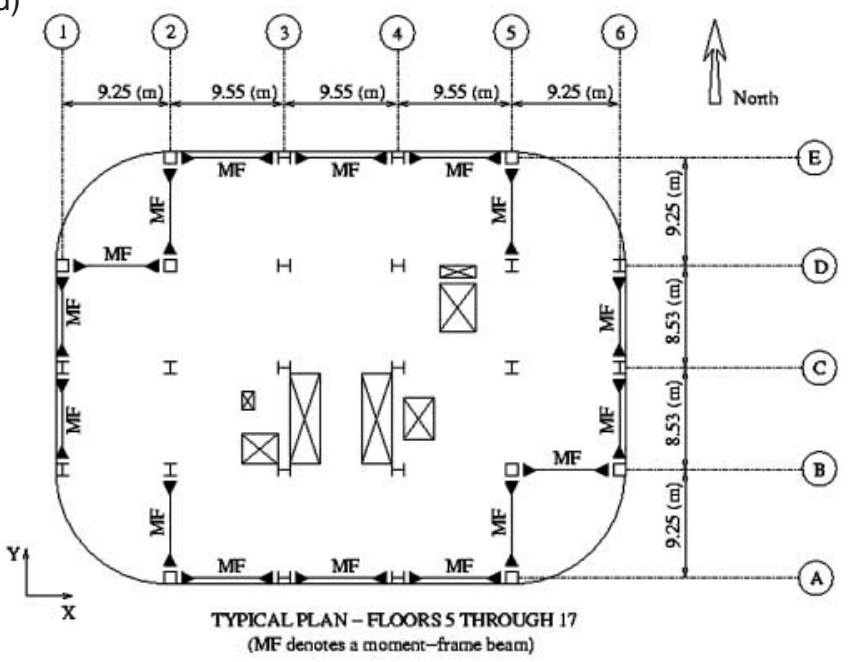

Figure 2. Structural models of the two buildings under study: (a) isometric view of the existing building (designed using the 1982 Uniform Building Code), (b) isometric view of the new building (redesigned using the 1997 Uniform Building Code), (c) plan view of a typical floor of the existing building showing the location of columns and moment-frame (MF) beams, and (d) plan view of a typical floor of the redesigned (new) building showing the location of columns and moment-frame beams. Note the greater number of moment-frame bays in the redesigned building.

higher resolution, and therefore the numerical cost would be high.

The second commonly used seismological approach consists of generating broadband ground motion through empirical methods that combine a stochastic approach at high frequencies with a deterministic approach at low fre- quencies (e.g., Graves and Pitarka, 2003; Graves, 2005). These methods are still nascent in their development. They are tailored for a given earthquake and have to be retuned on a case-by-case basis. Being empirical, they cannot be proved or validated consistently for various types of earthquakes. 
In this study, we take a deterministic approach to simulate ground motion based on the spectral-element method (e.g., Komatitsch and Tromp, 1999). The numerical simulations, which account for 3D variations of seismic-wave speeds and density, topography and bathymetry, and attenuation, are carried out using our open-source seismic-wave propagation package SPECFEM3D (www.geodynamics. org). The methodology adopted therein has been shown to reliably model ground motion down to a period of approximately $2 \mathrm{sec}$ using data from recent earthquakes (Komatitsch et al., 2004; Liu et al., 2004). The simulations do not consider scattering of the wave field from city buildings (e.g., Clouteau and Aubry, 2001).

\section{Building Damage Analysis}

The nonlinear time-history analyses of the building models are carried out using a finite-element program, FRAME3D (Krishnan, 2003a; see www.frame3d.caltech. edu for details). The particular 3D elements used by the program to model beams, columns, and joints in buildings have been shown to simulate damage accurately and efficiently (Krishnan, 2003b). Material nonlinearity resulting in flexural yielding, strain hardening, and ultimately rupturing of steel at the ends of beams and columns, and shear yielding in the joints (also known as panel zones) is included (Krishnan and Hall, 2006a,b). When the forces from an earthquake displace a building laterally $(\Delta)$, the gravity loads $(P)$ acting vertically downward cause a second-order overturning moment on the structure about its base, in addition to the overturning moment caused by the lateral forces themselves. This is termed the $P-\Delta$ effect and can lead to global instability of the building. The FRAME3D program incorporates geometric nonlinearity, which enables the modeling of the global stability of the building, accounting for $P-\Delta$ effects accurately. The fracture mode of failure is included in connections, but local flange buckling in beams and columns is not. Column splices can be incorporated into the model, but they are excluded in this study. Soil-structure interaction (SSI; e.g., Stewart et al., 1998; Trifunac et al., 2001) is not included in the analyses. Dynamic nonlinear SSI is not a wellunderstood phenomenon because of the lack of recorded data and the difficulty in designing accurate numerical tools to study it. One of the few real-world examples of extensive SSI research is a 14-story reinforced concrete storage building in Hollywood constructed in 1925 (Serino, 1989; Fenves and Serino, 1990; Trifunac et al., 2001). These studies indicate that the change in various structural-response parameters in this building during the 1 October 1987, magnitude 5.9 Whittier Narrows earthquake due to SSI could have been up to $20 \%$. SSI is an active area of research and should be incorporated into future studies of this kind.

\section{Assessing Building Damage}

The primary structural-response parameter that is used to evaluate structural performance is the interstory drift, which is the difference in displacement between the top and bottom of a story normalized by its height. The interstory drift is a good indicator of how far the building is from $P-\Delta$ instability and collapse. It is also closely related to the plastic rotation demand on individual beam-column connection assemblies, that is, the greater the yielding in the beams, columns, and joints, the greater this interstory drift would be, reducing the stability of the building.

Because there are very few usable data to assess the performance of tall buildings based on calculated drifts, we take an empirical approach proposed by the Federal Emergency Management Agency (FEMA). For rehabilitation of existing buildings, FEMA 356 (FEMA, 2000a) defines three performance levels: Immediate Occupancy (IO) refers to a postearthquake damage state in which very limited structural damage has occurred. The risk of life-threatening injury as a result of structural damage is very low, and although some minor structural repairs may be appropriate, these would generally not be required prior to reoccupancy. Life Safety (LS) is a postearthquake damage state that includes damage to structural components but retains a margin against onset of partial or total collapse. Collapse Prevention (CP) refers to a postearthquake damage state that includes damage to structural components such that the structure continues to support gravity loads but retains no margin against collapse. For existing buildings, the interstory drift limits for the IO, LS, and CP performance levels specified by FEMA are 0.007 , 0.025 , and 0.05 , respectively. For the design of new steel moment-frame buildings, FEMA 350 (FEMA, 2000b) defines only two performance levels, the IO and CP levels. For buildings taller than 12 stories, the interstory drift limits for these levels as specified therein are 0.01 and 0.06 , respectively.

In the existing building, we also take into account the fracture mode of failure in the beam-to-column connections that was widely observed during the Northridge earthquake. The details of the fracture models can be found in Krishnan et al. (2005). The fracture index representing the percentage of connections in the building that fractured is also used in this study to assess existing building performance. Since the Northridge earthquake, this defect has been corrected and we do not expect this mode of failure to happen in buildings built recently or today.

\section{Validation of Numerical Procedures}

The magnitude 6.71994 Northridge earthquake was widely recorded at seismic stations in southern California. Although many research groups have determined kinematic fault models by fitting seismic-waveform data (e.g., Hartzell et al., 1996; Wald et al., 1996), we use a wavelet transform approach (Ji et al., 2002) that can extract more information about slip heterogeneity by simultaneously considering both the time and frequency characteristics of the waveforms. The resulting finite-source model is shown in Figure 3. Using the spectral-element method (e.g., Komatitsch and Tromp, 1999) we simulate ground motion generated by our finitesource model of the Northridge earthquake. 


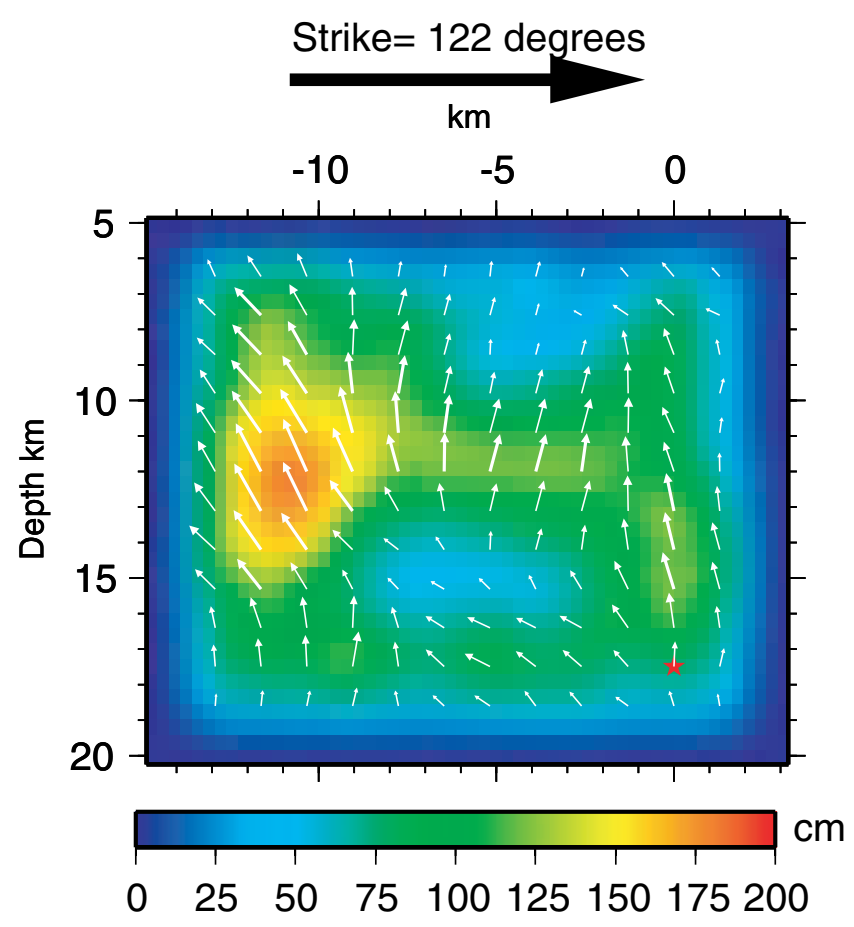

Figure 3. Slip model for the 17 January 1994, magnitude 6.7 Northridge earthquake determined with a wavelet transform approach. The red star denotes the hypocenter and the white arrows denote the slip vector. The dip angle of the fault is 40 degrees (see Fig. 1 for the surface projection of the fault).

For the Northridge simulation, in addition to the 636 sites considered in this study, we compute seismograms at seismic stations in southern California that actually recorded the shaking during the earthquake. The synthetic seismograms (red) are compared against the recorded data (black) at distant stations (Fig. 4a) and at nearby stations north of the fault (Fig. 4b). All the waveforms are lowpass filtered at a corner period of $2 \mathrm{sec}$. The synthetic seismograms capture the large pulses at the nearby stations, and there is a very good match in most waveforms corresponding to distant stations.

Although there is sufficient ground-motion data to validate the seismological component of our procedure, the same is not true of tall-building performance. Not many tall buildings in the region were instrumented at the time. One building that was instrumented was the previously described 18-story steel moment frame building in Woodland Hills built in 1984. Many connections in the lateral force-resisting moment frames of this building fractured (SAC, 1995b). There was a three-component accelerometer on the 18th floor of the building that recorded the floor acceleration (Darragh et al., 1994). Unfortunately, the closest free-field seismometer was the Oxnard Boulevard station (WHOX) in Woodland Hills, located about $800 \mathrm{~m}$ away from the building. We analyze the building model for shaking from the recorded three-component ground motion (Darragh et al., 1994) using FRAME3D.
The computed displacements at the 18th floor in the north-south and east-west directions are compared with the corresponding measured displacements in Figure $4 \mathrm{c}$ and $\mathrm{d}$. The computed peak displacement in the north-south direction is within $5 \%$ of the measured displacement, but the peak displacement in the east-west direction is off by a factor of 2. There is a minor lengthening of the period in the measured displacement that is not captured by the computed displacements. Also, the measured displacement attenuates faster than the computed displacement. These differences could be due to any or all of the following factors: the ground motion used in the analysis was not recorded at the base of the building but $800 \mathrm{~m}$ away; the instrument at the roof was maintained by the owner of the building and its reliability is therefore uncertain; rocking of the building about its base (due to the finite stiffness of the soil), which is not included in the fixed-base structural model, could contaminate the displacement record measured at the roof and the observed period may actually be a combination of purely translational and rocking modes; as damage accumulates in a building during an earthquake, (nonhysteretic) damping increases significantly. In our structural model, while hysteretic damping is modeled accurately in a nonlinear fashion, nonhysteretic supplemental damping is considered to be viscous and linear, and as damage accumulates, it does not increase correspondingly. Greater details, including the comparison of observed and computed distributions of fractures in the various moment frames, can be found in Krishnan et al. (2005).

From this description, the limitations of our validation studies are obvious. Whereas the validation is based on the magnitude 6.7 Northridge earthquake, the scenario earthquakes simulated below are of magnitude 7.9 (i.e., with energy release about two orders of magnitude greater). Similarly, the source mechanism of the Northridge earthquake was a thrust mechanism that did not break the surface, whereas the San Andreas simulation has a strike-slip source mechanism with surface break. Furthermore, the amount of data collected during the Northridge earthquake, especially with regard to buildings, is fairly limited, and this restricts the extent to which the numerical procedures can be convincingly validated. Having said this, validation is a critical element of studies such as this and data from future earthquakes will inevitably play a crucial role in improving the numerical procedures.

\section{Effect of Excluding Ground Motion High-Frequency Content}

As mentioned earlier, ground motion simulated using SPECFEM3D in the Los Angeles basin has been shown to be accurate down to a period of approximately $2 \mathrm{sec}$. Because of this limitation, all the computed broadband time histories are lowpass filtered with the corner period at $2 \mathrm{sec}$ (in practice, bandpass filtered between $2 \mathrm{sec}$ and $1000 \mathrm{sec}$ ). The filtered ground-motion records are used as input to the building analysis software. However, building response is a 
(a)

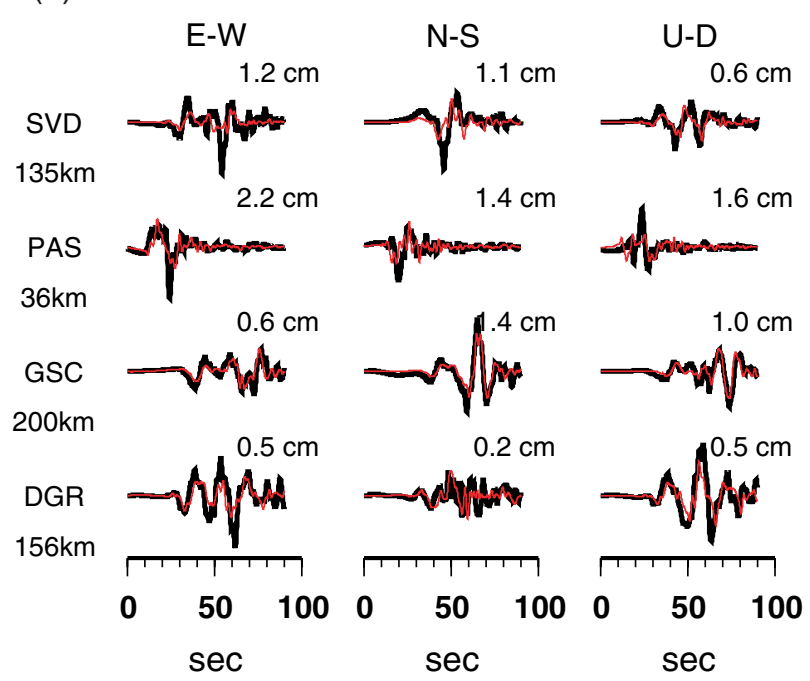

(c)

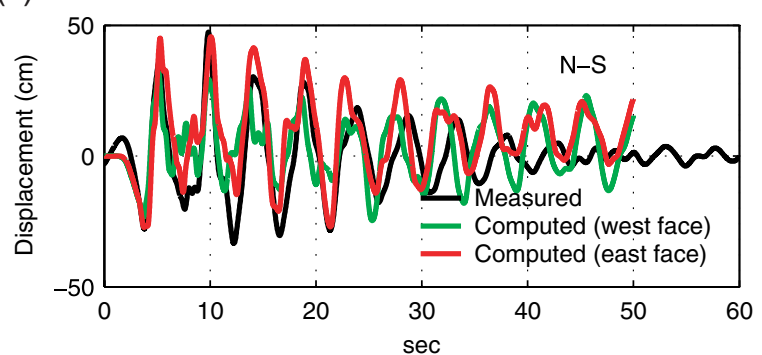

(b)

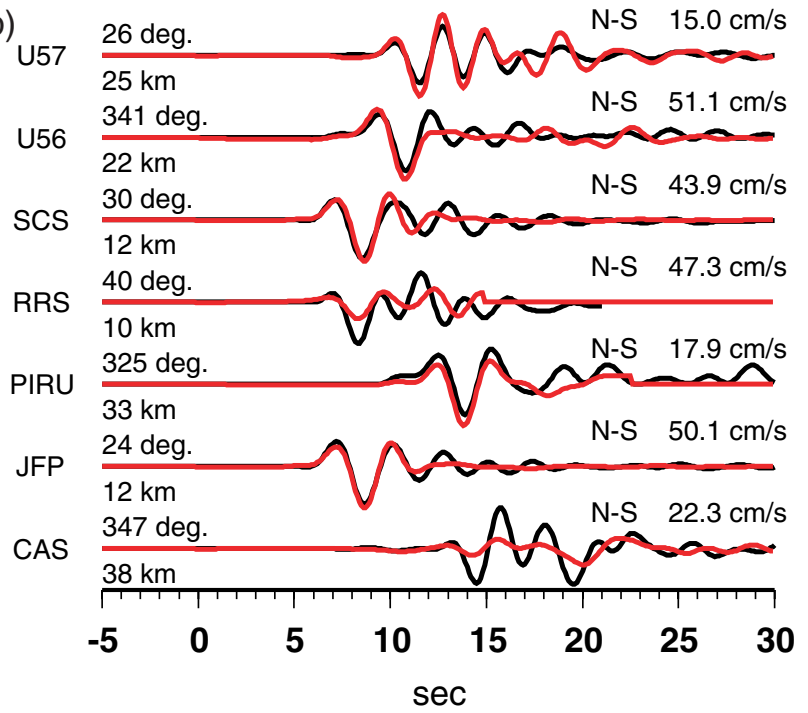

(d)

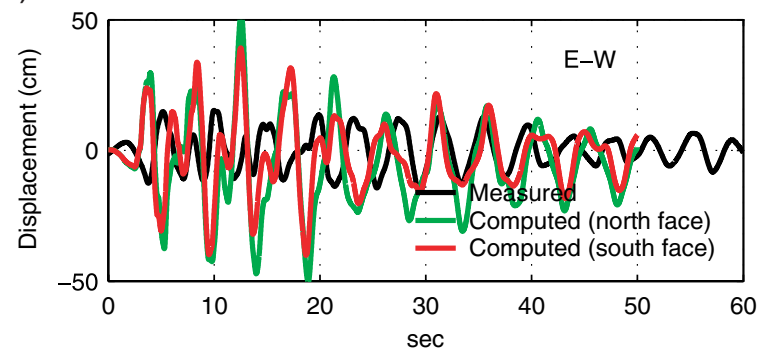

Figure 4. Simulation of the 17 January 1994, magnitude 6.7 Northridge earthquake. (a) Data (black) versus synthetic seismograms (red) - distant stations. (b) Data versus synthetic seismograms - nearby stations north of the rupture. (c) and (d) Measured 18th floor north-south and east-west displacements versus corresponding computed displacements using the unfiltered WHOX record (station located 0.5 mile from building)—existing building in Woodland Hills.

function of the entire frequency band of the ground motion with the building's higher modes corresponding to shorter periods excited by high-frequency ground motion. The question arises, therefore, as to what the effect of excluding the high-frequency ground motion is on the response of the considered buildings. Because dominant modes of tall buildings of the type considered here have periods greater than $2 \mathrm{sec}$ it is theorized that the effect of the higher frequencies on the ground motion may not have a significant impact on their response. To confirm this, we perform the following study: we take a total of 13 three-component records from the 21 September 1999, magnitude 7.7 Chi-Chi earthquake in Taiwan, and the 25 September 2003, magnitude 8.3 Tokachi-Oki earthquake in Japan. We lowpass filter these records with a corner period of $2 \mathrm{sec}$. We then compare the responses of the existing and redesigned buildings to the filtered and unfiltered records. Shown in Figure 5 are the peak drift ratios computed in the existing and redesigned buildings using the filtered records plotted against those computed using the corresponding unfiltered records. If the high-frequency ground motion had no effect whatsoever on the response of the buildings, then all the points would fall on the diagonal. The fact that all the points are aligned quite closely with the diagonal indicates that the effect of highfrequency ground motion (the range of frequencies not included in our simulation) on the tall-building response (for the buildings considered here) is not significant and can be safely ignored. In essence the initial $S$ wave damages the tall building and this leads to a softening of the structure, thus shifting the natural frequency spectrum of the building further into the long-period regime, reducing even more the effect of the high-frequency content in the ground motion.

\section{San Andreas Simulation: North-to-South Rupture}

\section{Source Model}

For the San Andreas simulations it is critical to have a realistic source model (slip distribution in time along the fault). The Denali fault system in Alaska is geometrically similar to the San Andreas fault. On 3 November 2002, a magnitude 7.9 earthquake occurred on this fault system. It initiated as a magnitude 7.1 thrust event on the Susitna Gla- 
(a)

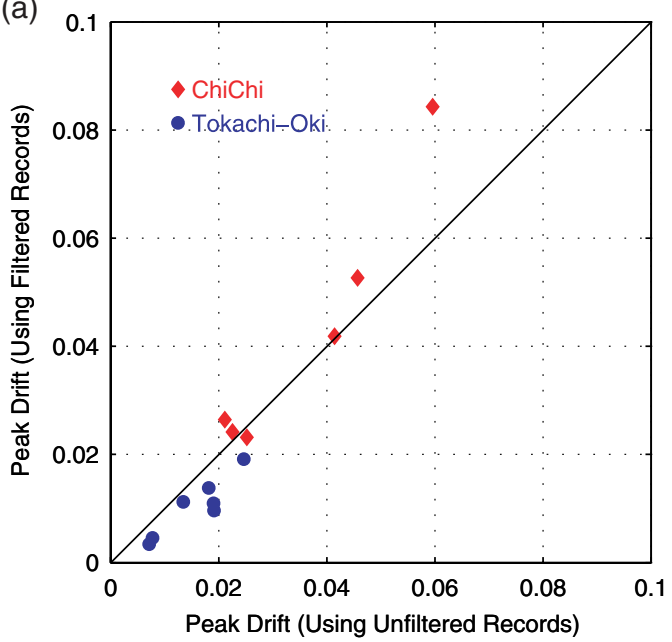

(b)

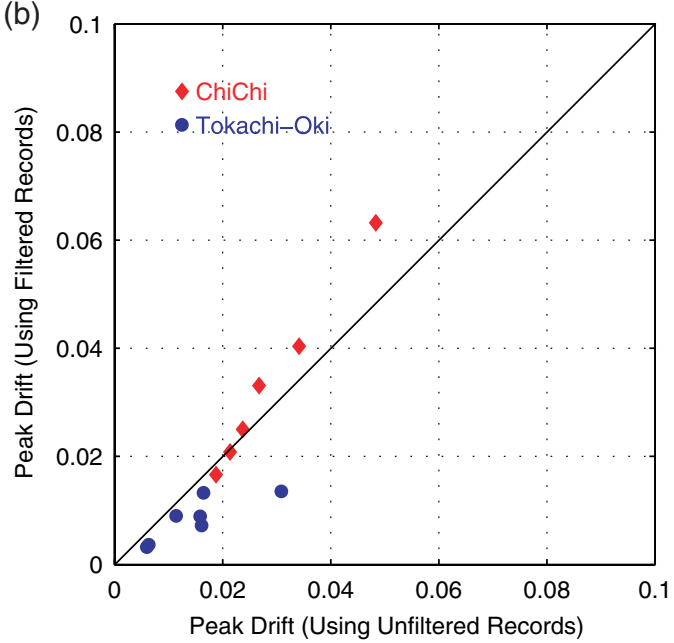

Figure 5. Analyses of the existing and redesigned buildings subject to 13 unfiltered and lowpass-filtered records from the 21 September 1999, magnitude 7.7 Chi-Chi earthquake in Taiwan, and the 25 September 2003, magnitude 8.3 Tokachi-Oki earthquake in Japan: computed peak drifts in the building using filtered records versus those using unfiltered records. The close alignment of the points with the diagonal indicates that the effect of higher-frequency ground motion (periods $\leq 2 \mathrm{sec}$ ) on the response of the tall buildings considered in this study is not significant and can be safely ignored.

cier fault, quickly changed to a strike-slip mode of rupture, and propagated southeastward along the Denali fault for $218 \mathrm{~km}$ before jumping to the Totschunda fault and continuing further for about $76 \mathrm{~km}$ (Eberhart-Phillips et al., 2003). We have studied the slip distribution of this earthquake (Fig. 6a) using teleseismic body waves and strong-motion waveforms as well as Global Positioning System (GPS) vectors (Ji et al., 2003). Here, we have mapped the slip on the Denali and Totschunda faults (290 km long), amounting to a moment magnitude of 7.9, onto the San Andreas fault, with the rupture initiating at Parkfield and progressing in a southeasterly direction for a distance of about $290 \mathrm{~km}$ (Fig. 1 inset). The maximum depth of rupture is about $20 \mathrm{~km}$. The surface slip grows slowly to $7.4 \mathrm{~m}$ and then drops off drastically toward the end of the rupture (Fig. 6b), which incidentally is contrary to what happened during the 1857 San Andreas earthquake, where the slip along the fault is deduced to have grown quickly to a peak value of about $9.5 \mathrm{~m}$ and then dropped off gradually (Sieh, 1978b). The peak slip at depth is about $12 \mathrm{~m}$, and the peak particle velocity is about $4.3 \mathrm{~m} \cdot \mathrm{sec}^{-1}$. Note that because particle velocity is not constrained as well as slip in the inversion, we have also considered a scenario in which we artificially cap the particle velocity at $1 \mathrm{~m} \cdot \mathrm{sec}^{-1}$. The resulting ground motions in the region of interest (far away) are not significantly different from the uncapped particle velocity version in the context of the present analysis and are therefore not shown here. To study the effect of directivity and the spatial distribution of slip on basin ground motions, we also consider a scenario with rupture propagating from south to north and terminating at Parkfield, with the peak slip occurring close to Parkfield. The surface slip for this scenario is shown in Figure 6c.

\section{Ground Motion}

Using the spectral-element method, we compute seismograms at each of the 636 hypothetical tall-building sites (Fig. 1). The minimum $S$-wave velocity in the Harvard-LA basin model is $687 \mathrm{~m} \cdot \mathrm{sec}^{-1}$. The horizontal size of the mesh cells at the surface is approximately $270 \mathrm{~m}$ in each direction. The resulting number of grid points per $S$ wavelength is about 5. The timestep used for the computations is $9 \mathrm{msec}$, with a total number of 30,000 steps, that is, a total duration of $270 \mathrm{sec}$. Shown in Figures $7 \mathrm{a}-\mathrm{c}$ and d-f are maps of the three components of peak velocity and displacement, respectively, lowpass filtered at a corner period of $2 \mathrm{sec}$. The solid circles in these maps correspond to the cities shown in Figure 1. The San Fernando valley experiences severe shaking. As the rupture proceeds south from Parkfield and hits the bend in the San Andreas fault, it sheds off a significant amount of energy into the region that is directly in front of it, which happens to be the San Fernando valley (see www. ce.caltech.edu/krishnan for a movie of the rupture and seismic-wave propagation). A good portion of this energy spills over into the Los Angeles basin, with many cities along the coast, such as Santa Monica and Seal Beach, and more inland areas, going east from Seal beach toward Anaheim, experiencing long-duration shaking. In addition, the tail end of the rupture sheds energy from $S H /$ Love waves into the Baldwin Park-La Puente region, which is bounded by a line of mountains, creating the San Gabriel basin and further amplifying the ground motion. The peak velocity is of the order of $1 \mathrm{~m} \cdot \mathrm{sec}^{-1}$ in the Los Angeles basin, including downtown Los Angeles, and $2 \mathrm{~m} \cdot \mathrm{sec}^{-1}$ in the San Fernando valley. The map of peak displacements has charac- 
(a)
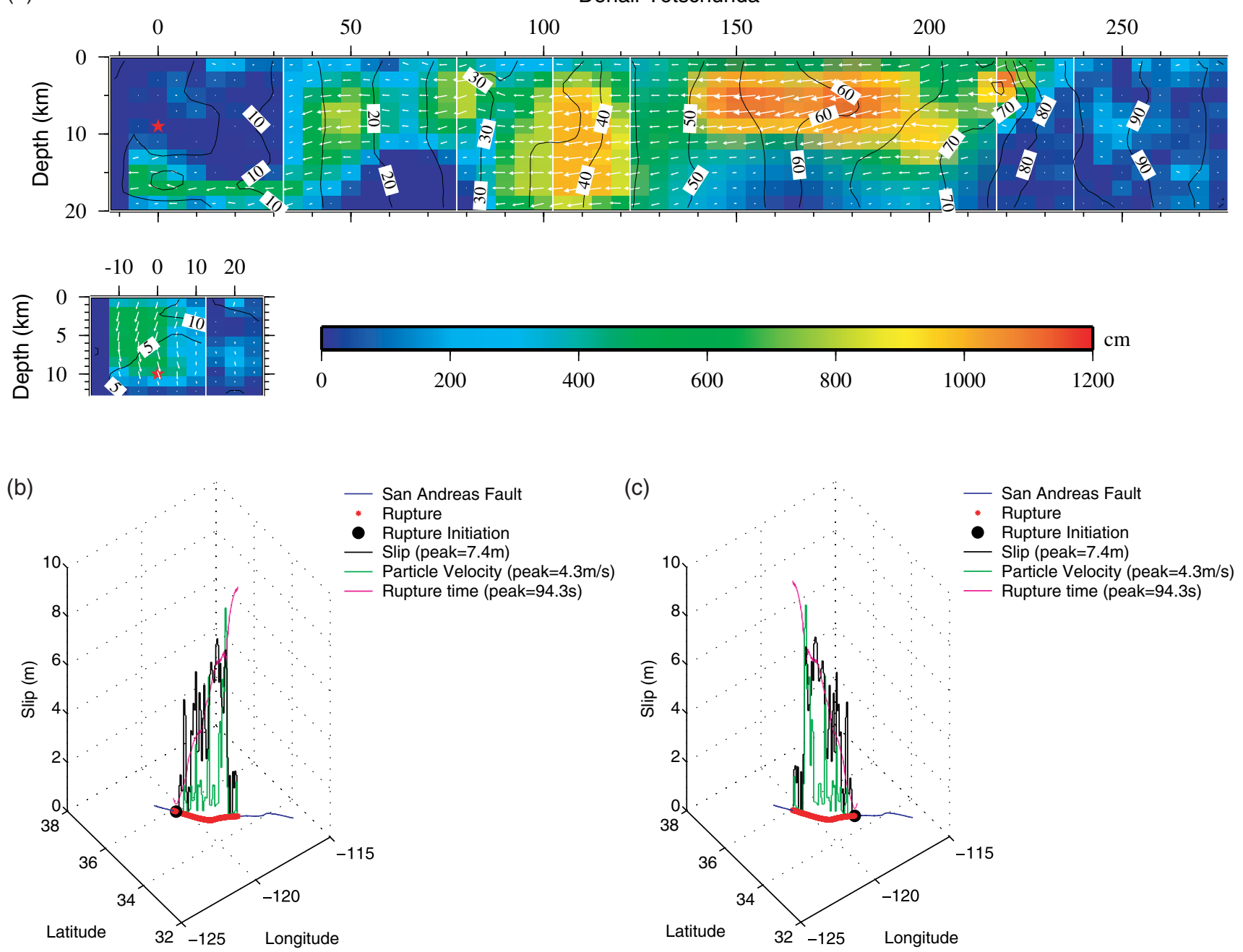

Figure 6. (a) Slip distribution of the 3 November 2002, magnitude 7.9 Denali, Alaska, earthquake constrained by teleseismic body and strong-motion waveforms as well as GPS vectors. The color scheme reflects the slip amplitude and contours reflect the rupture initiation time. The hypocenter is indicated by the red star. White arrows denote the slip direction and magnitude. (b) and (c) Surface slip, particle velocity, and rupture time for the simulated magnitude 7.9 earthquake on the San Andreas fault in the case of north-to-south and south-to-north ruptures, respectively.

teristics similar to that of the peak velocities, with significant displacements in the basins but not in the mountains. The peak displacements are in the neighborhood of $1 \mathrm{~m}$ in the Los Angeles basin and $2 \mathrm{~m}$ in the San Fernando valley.

\section{Existing Building Response}

To study the effects of the simulated ground motion on 18-story steel moment-frame buildings located at each of the 636 sites shown in Figure 1, we analyze models of the existing and redesigned buildings described earlier, with the building $Y$ direction aligned with the geographical north direction. As before, the analyses are performed using the FRAME3D program (Krishnan, 2003a). We use the peak interstory drift and the percentage of fractured connections to evaluate the existing building performance, whereas we use only the former to evaluate the performance of the redesigned building.

To put our results for existing buildings in perspective, note that although the population of tall buildings in southern California is widespread, a major fraction is located in downtown Los Angeles, the mid-Wilshire district (Beverly Hills), west Los Angeles, and Santa Monica. There are quite a few tall buildings spread across the San Fernando valley as well (along the 101 freeway), for example, in Camarillo, Woodland Hills, and Canoga Park, and 30-40 tall buildings in Orange County (comprising the cities of Orange, Irvine, Costa Mesa, Newport Beach, Anaheim, Santa Ana, Garden Grove, etc.). A host of new tall buildings is being planned 
(a)

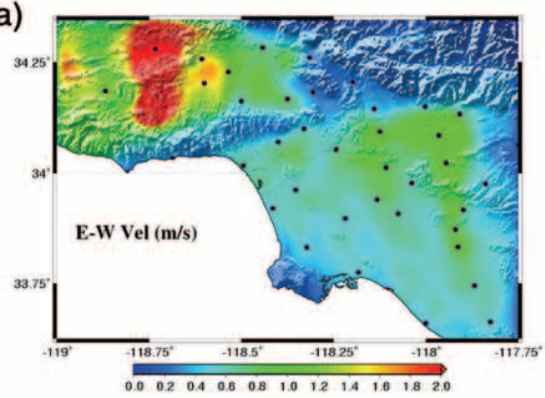

(d)

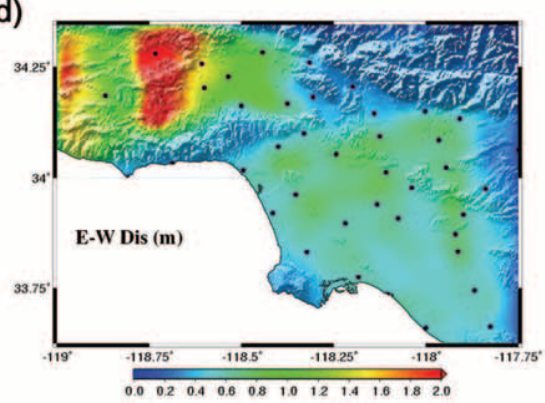

(g)

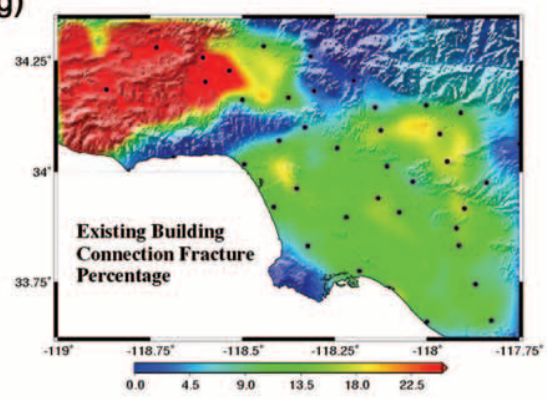

(b)

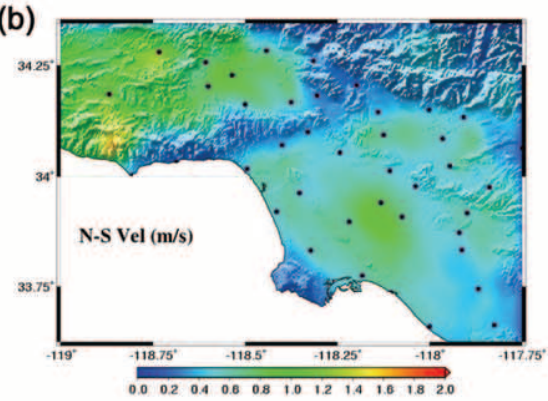

(e)

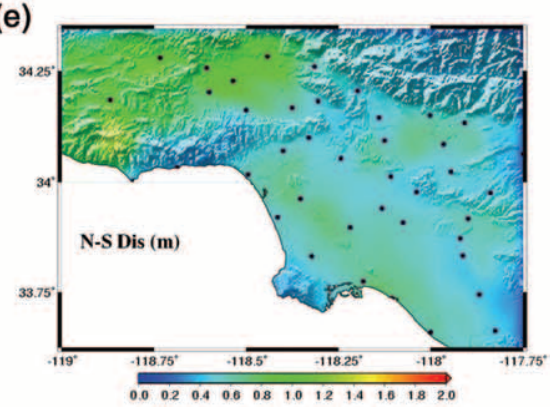

(h)

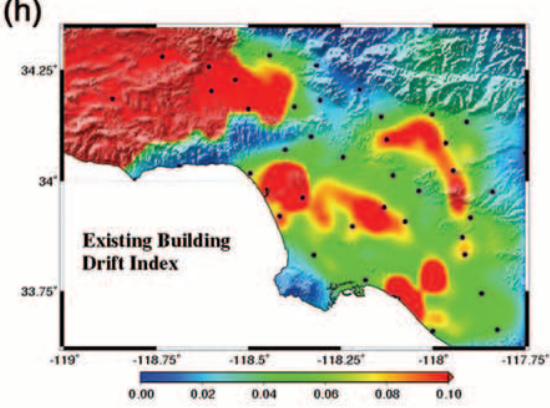

(c)

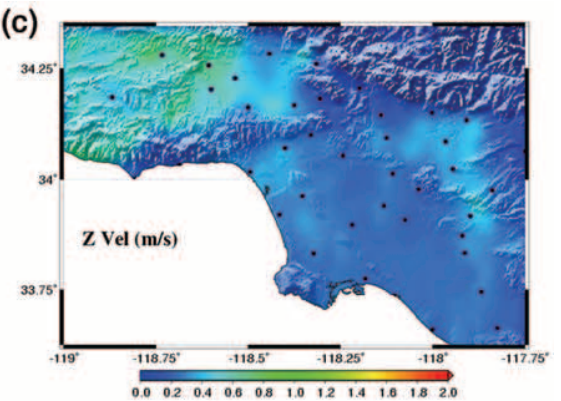

(f)

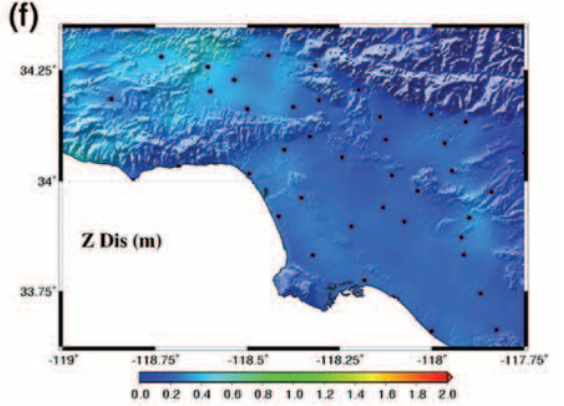

(i)

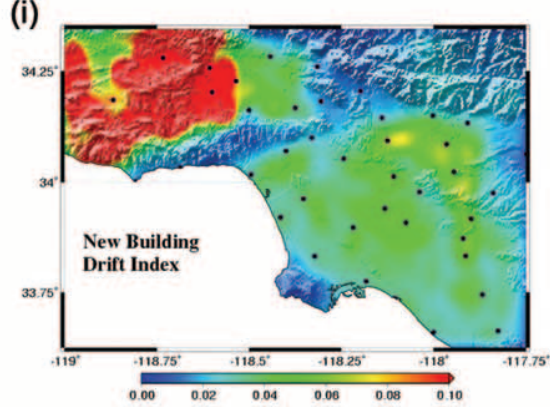

Figure 7. Hypothetical $M_{\mathrm{w}} 7.9$ earthquake (north-to-south rupture) on the San Andreas fault: ground motion and building performance. Shown are the east-west, northsouth, and vertical components of the peak ground velocities (a, b, and c, respectively) and displacements ( $\mathrm{d}$, e, and $\mathrm{f}$, respectively) of the synthetic seismograms lowpass filtered with a corner period of $2 \mathrm{sec}$, the percentage of connections in the existing building where fractures occur (of 710 connections with the two ends of each momentframe beam and column defined as connections) (g), and the peak interstory drift in the existing and redesigned buildings ( $h$ and i, respectively). Peak interstory drifts beyond 0.06 are indicative of severe damage, while drifts below 0.01 are indicative of minimal damage not requiring any significant repair.

in Orange County with 13 proposed high-rises in the cities of Anaheim and Santa Ana.

The results of our building analyses (see www.ce. caltech.edu/krishnan for movies of buildings swaying under the earthquake resulting in permanent tilt or collapse) corresponding to a north-to-south rupture of the San Andreas fault are summarized in Figure $7 \mathrm{~g}$ and $\mathrm{h}$ for the existing 18story steel building. Figure $7 \mathrm{~g}$ shows the percentage of connections where fracture occurs in the existing building. At least $25 \%$ of the connections in this building fracture when it is located in the San Fernando valley. Note that the scale saturates at $25 \%$ and that this number is exceeded at many locations. About $10 \%$ of the connections fracture in the building when it is located in downtown Los Angeles and the mid-Wilshire district (Beverly Hills), whereas the numbers are about $20 \%$ when it is located in Santa Monica, west Los Angeles, Inglewood, Alhambra, Baldwin Park, La Puente, Downey, Norwalk, Brea, Fullerton, Anaheim, and Seal Beach. Figure $7 \mathrm{~h}$ shows the peak interstory drift that occurs in the existing building. Consistent with the extent of observed fractures, the peak drifts in the existing building exceed 0.10 when it is located in the San Fernando valley, Baldwin Park and neighboring cities, Santa Monica, west Los Angeles and neighboring cities, Norwalk and neighboring cities, and Seal Beach and neighboring cities, which is well into the postulated collapse regime (FEMA, 2000a). Note that the scale saturates at 0.10 and that the drifts far exceed this number in many locations in these regions. When 
located in downtown Los Angeles and the mid-Wilshire district, the building would barely satisfy the collapse prevention criteria set by FEMA (FEMA 2000a, b) with peak drifts of about 0.05 .

Greater details of the response of the buildings, including location of damage in the building, are provided online (Krishnan et al., 2005). One of the key observations is that the peak interstory drifts in the middle third and bottom third of the existing building are far greater than in the top third, indicating that the damage is localized in the lower floors. This localization of damage in the lower floors rather than the upper floors could potentially be worse because of the risk of more floors pancaking on top of each other if a single story gives way.

\section{Redesigned Building Response}

Figure $7 \mathrm{i}$ shows the peak interstory drift that occurs in the redesigned 18-story steel building. The performance of this building is noticeably better than the existing building for the entire region. However, note that the new building has significant drifts indicative of serious damage when located in the San Fernando valley or the Baldwin Park area. When located in coastal cities (such as Santa Monica or Seal Beach), the Wilshire corridor (west Los Angeles, Beverly Hills), the neighborhoods of Downey and Norwalk, or the rapidly developing Orange County cities of Anaheim and Santa Ana, it exhibits peak drifts of about 0.05 , once again barely satisfying the FEMA collapse prevention criteria (FEMA, 2000a, b). In downtown Los Angeles it does not undergo much damage in this scenario. Thus, even though this building has been designed according to the latest code, it suffers damage that would necessitate closure for some time after the earthquake in most areas, but this should be expected because this is a large earthquake and building codes are written to limit the loss of life and ensure "collapse prevention" for such large earthquakes, but not necessarily limit damage.

Note that for the north-to-south rupture of the San Andreas fault considered here, if the slip distribution along the fault were like the 1857 earthquake, that is, rising quickly to the peak value and then gradually dropping off (Sieh, 1978b), instead of the other way around, the results could be quite different, that is, we may see significantly reduced displacements. Furthermore, directivity can have a significant impact on ground shaking and the resulting building damage. For example, for a south-to-north rupture of the same earthquake described in the next section, building damage is far less severe.

\section{San Andreas Simulation: South-to-North Rupture}

\section{Ground Motion}

A natural question to ask is what would happen if the rupture were to proceed from south to north instead of the other way around, with the peak slip occurring close to Parkfield. The results of such a scenario (see Fig. $6 c$ for surface slip) indicate that ground shaking would be far less severe. This demonstrates the effect of directivity and slip distribution in dictating the level of ground shaking and the associated damage to buildings.

Shown in Figures $8 \mathrm{a}-\mathrm{c}$ and $\mathrm{d}-\mathrm{f}$ are the peak velocities and displacements, respectively, of the ground-motion time histories lowpass filtered at a corner period of $2 \mathrm{sec}$. Although the San Fernando valley still experiences the most shaking, ground motion in Santa Monica and to some extent Baldwin Park is comparable in magnitude. The peak velocities are of the order of $0.6 \mathrm{~m} \cdot \mathrm{sec}^{-1}$ in the San Fernando valley, $0.5 \mathrm{~m} \cdot \mathrm{sec}^{-1}$ in Santa Monica and El Segundo, and $0.3 \mathrm{~m} \cdot \mathrm{sec}^{-1}$ in the remaining parts of Los Angeles and Orange Counties. The corresponding peak displacements are in the range of 0.5-0.6 m in the San Fernando valley, 0.4$0.5 \mathrm{~m}$ in Santa Monica and El Segundo, and $0.3-0.4 \mathrm{~m}$ in the remaining parts of Los Angeles and Orange Counties.

\section{Existing Building Response}

The reduced level of shaking is reflected in the results of the building analyses. Figure $8 \mathrm{~g}$ shows the percentage of connections where fracture occurs in the existing building model. Fracture occurs in 3-7\% of the connections in this building when it is located in the San Fernando valley. About $4-5 \%$ of the connections fracture in the building model when it is located in Santa Monica or El Segundo. In most other areas, there is little or no risk associated with moment-frame connection fractures. Figure $8 \mathrm{~h}$ shows the peak interstory drift that occurs in the existing building. Peak interstory drifts beyond 0.06 are indicative of severe damage, whereas drifts below 0.01 are indicative of minimal damage not requiring any significant repairs. Peak drifts are in the neighborhood of 0.03 in the San Fernando valley, Santa Monica, El Segundo, and Baldwin Park. Peak drifts in most other areas are less than 0.02. As for the north-to-south rupture scenario, the peak interstory drifts in the middle third and bottom third of the existing building are greater than in the top third, which indicates that the damage is localized in the lower floors.

\section{Redesigned Building Response}

The performance of the newly designed 18-story steel building is slightly better than the existing building for the entire region. Figure 8i shows the peak interstory drift that occurs in the building. Peak drifts are in the neighborhood of 0.02-0.03 when the building model is located in the San Fernando valley, Santa Monica, El Segundo, and Baldwin Park. Building peak drifts in most other areas are in the neighborhood of 0.01 , well below the criterion for LS performance level set by FEMA. 
(a)

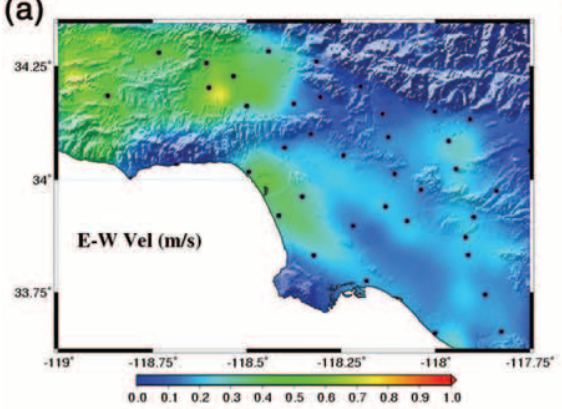

(d)

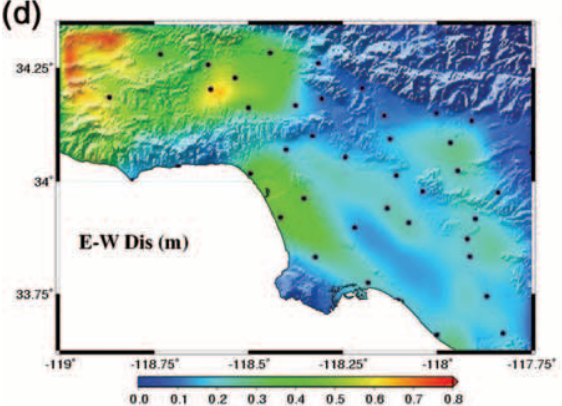

(g)

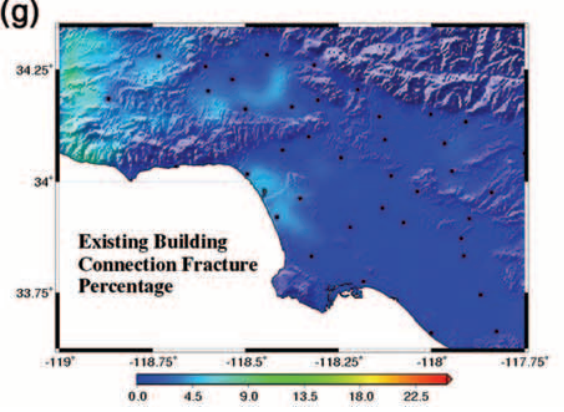

(b)

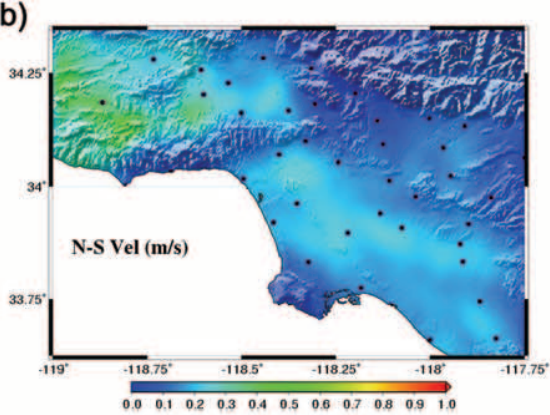

(e)

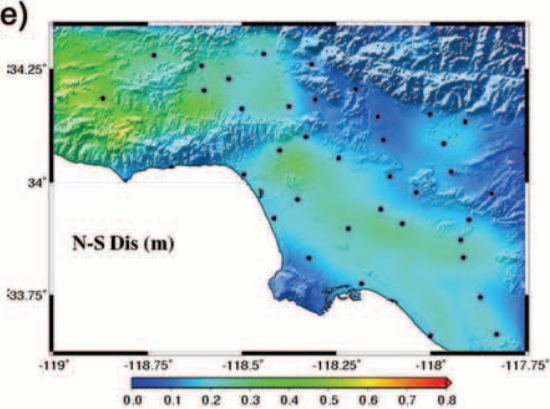

(h)

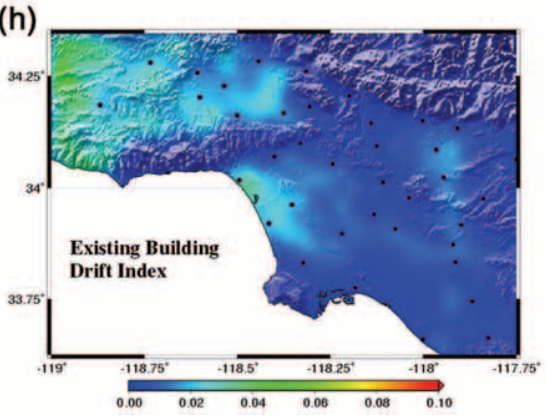

(c)

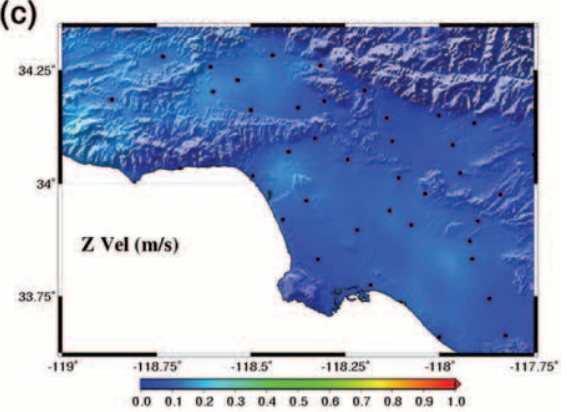

(f)

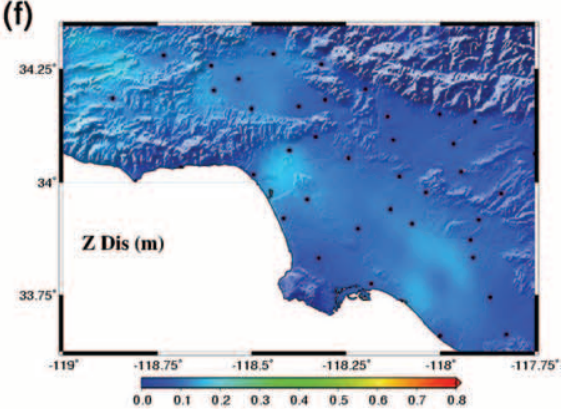

(i)

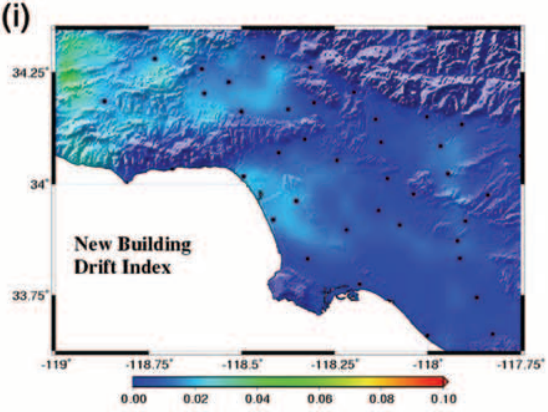

Figure 8. Hypothetical $M_{\mathrm{w}} 7.9$ earthquake (south-to-north rupture) on the San Andreas fault: ground motion and building performance. Shown are the east-west, northsouth, and vertical components of the peak ground velocities ( $a, b$, and c, respectively) and displacements (d, e, and f, respectively) of the synthetic seismograms lowpass filtered with a corner period of $2 \mathrm{sec}$, the percentage of connections in the existing building where fractures occur (of 710 connections with the two ends of each momentframe beam and column defined as connections) (g), and the peak interstory drift in the existing and redesigned buildings ( $\mathrm{h}$ and $\mathrm{i}$, respectively). The peak drifts in existing and new buildings are in the range of 0.02-0.04, indicating that there is no significant danger of collapse. However, damage would still be significant enough to warrant building closures and compromise LS in some instances.

\section{Conclusions}

We have performed simulations of two hypothetical magnitude 7.9 earthquakes on the San Andreas fault and assessed the resulting damage to models of an existing and a redesigned 18-story steel moment-frame building. We use the finite-source model of the 2002 Denali, Alaska, earthquake by mapping it to the San Andreas fault and computed ground motions in southern California at 636 representative sites for two rupture scenarios: north-to-south rupture initiating at Parkfield and south-to-north rupture terminating at Parkfield. We have analyzed 3D computer models of an existing building in Woodland Hills that was damaged during the 1994 Northridge earthquake and the same building redesigned according to the 1997 Uniform Building Code for the three-component ground motion (lowpass filtered with a corner period of $2 \mathrm{sec}$ ) at each of the 636 sites. The performance of the building models is classified based on the peak interstory drift ratio. The details of the study have been compiled into a comprehensive online report (Krishnan et al., 2005). The following are the key findings of our study.

1. For the north-to-south rupture scenario, the peak ground velocity is of the order of $2 \mathrm{~m} \cdot \mathrm{sec}^{-1}$ in the San Fernando Valley and $1 \mathrm{~m} \cdot \mathrm{sec}^{-1}$ in the Los Angeles basin, whereas the corresponding values for the south-to-north rupture 
scenario are $0.6 \mathrm{~m} \cdot \mathrm{sec}^{-1}$ and $0.4 \mathrm{~m} \cdot \mathrm{sec}^{-1}$, respectively.

2. For the north-to-south rupture scenario, the peak ground displacement is of the order of $2 \mathrm{~m}$ in the San Fernando Valley and $1 \mathrm{~m}$ in the Los Angeles basin, whereas the corresponding values for the south-to-north rupture scenario are $0.6 \mathrm{~m}$ and $0.4 \mathrm{~m}$, respectively. The stark contrast between the ground motions in the two cases is an illustration of the effects of directivity and slip distribution controlling the intensity of ground motion.

3. Under the ground motion generated by the north-to-south rupture, peak drifts in the existing building model far exceed 0.10 in the San Fernando Valley, Santa Monica, and west Los Angeles, Baldwin Park and neighboring cities, Compton and neighboring cities, and Seal Beach and neighboring cities. Peak drifts are in the 0.06-0.08 range in Huntington Beach, Santa Ana, Anaheim, and neighboring cities, whereas the values are in the 0.04 0.06 range for the remaining areas including downtown Los Angeles. Peak drifts exceeding 0.10 are indicative of probable collapse, and drifts exceeding 0.06 are indicative of severe damage. Peak drifts in excess of 0.025 could compromise LS.

4. The results for the redesigned building are better than for the existing building. While the peak drifts in many areas in the San Fernando valley still exceed 0.10, they are in the range of 0.04-0.06 for most cities in the Los Angeles basin. Although this may not conclusively be indicative of collapse, it certainly points to significant damage and may result in building closures.

5. Under the ground motion generated by the south-to-north rupture, the peak drifts in existing and redesigned building models are in the range of 0.02-0.04, suggesting that there is no significant danger of collapse. However, this is indicative of damage significant enough to warrant building closures and compromise LS in some instances.

The building analyses in this study are specific to two 18 -story steel moment-frame buildings, that is, an existing building designed according to UBC82 and a new building designed according to UBC97. Other buildings with varied configuration, constructed with other materials, or having distinct dynamic characteristics could have damage patterns quite different from the results presented here. In addition, there are significant uncertainties in the earthquake source characteristics, including the location of the hypocenter, slip distribution, rupture direction, etc. Furthermore, future studies striving toward the goal of a truly end-to-end simulation must attempt to include the top soil layer in the groundmotion simulations and soil-structure interaction in the structural analysis. The fact remains, however, that the potential for a large earthquake with a large amount of slip on the San Andreas fault exists, and with the current state of knowledge of the southern Californian geological structure, our study indicates that serious damage could occur in the two steel moment-frame buildings in at least one of the plausible scenarios.
The procedures presented in this article, integrating the fields of seismology and structural engineering, can be used to perform seismic-hazard assessment of specific engineered structures in a more quantitative manner than has been possible previously. For example, if a critical structure such as a hospital is to be built in downtown Los Angeles, a detailed model of the structure can be analyzed using simulated seismic waveforms generated by various plausible earthquakes on regional faults, and based on its performance informed decisions can be made to improve the structural design. Similar analyses can be performed to determine the risk posed to an existing structure. In each case, the applicability of the band-limited simulated ground motion for the analysis of the particular structure under consideration needs to be ascertained. By performing two analytical case studies of 18story steel moment-frame buildings subjected to two plausible simulated San Andreas earthquakes we have provided a proof-of-concept of how quantitative seismic-hazard assessment can be conducted in a more rigorous manner. Although our study is restricted to the modeling of the physical phenomena of earthquakes and structural damage, the results can be extended in the future to include economic and financial indicators. In addition, these types of analyses could benefit large cities in laying out emergency-response strategies in the event of a large earthquake, in undertaking appropriate retrofit measures for tall buildings, in formulating zoning regulations, and in developing better guidelines for new construction. Finally, they could provide seismic-risk parameters associated with existing and new construction to insurance companies, real estate developers, and individual property owners, so that they can make appropriate economic decisions.

\section{Acknowledgments}

We thank John F. Hall, Thomas H. Heaton, and Hiroo Kanamori of the California Institute of Technology, for their input during the course of this study, and the editor and reviewers for valuable comments that enhanced the article. The numerical simulations were performed on the Division of Geological \& Planetary Sciences Dell cluster at the California Institute of Technology, and the Seawulf cluster at the University of Toronto, Canada.

\section{References}

Agnew, D. C., and K. Sieh (1978). A documentary study of the felt effects of the great California earthquake of 1857. Bull. Seism. Soc. Am. 68, no. 6, 1717-1729.

Anderson, J. G., Y. Lee, Y. Zeng, and S. M. Day (1996). Control of strong motion by the upper 30 meters. Bull. Seism. Soc. Am. 86, 1749-1759.

Carlson, A. (1999). Three-dimensional nonlinear inelastic analysis of steel moment-frame buildings damaged by earthquake excitations. Technical Report EERL 1999-02, Earthquake Engineering Research Laboratory, California Institute of Technology, Pasadena, California.

Clouteau, D., and D. Aubry (2001). Modifications of the ground motion in dense urban areas. J. Comput. Acoust. 9, no. 4, 1659-1675.

Darragh, R., T. Cao, V. Graizer, A. Shakal, and M. Huang (1994). Los Angeles code-instrumented building records from the Northridge, California earthquake of January 17, 1994: processed release No. 1. 
Technical Report OSMS 94-17, California Strong Motion Instrumentation Program, California Department of Conservation, Division of Mines and Geology (now California Geological Survey), California. Eberhart-Phillips, D., P. J. Haeussler, J. T. Freymueller, A. D. Frankel, C. M. Rubin, P. Craw, N. A. Ratchkovski, G. Anderson, G. A. Carver, A. J. Crone, T. E. Dawson, H. Fletcher, R. Hansen, E. L. Harp, R. A. Harris, D. P. Hill, S. Hreinsdottir, R. W. Jibson, L. M. Jones, R. Kayen, D. K. Keefer, C. F. Larsen, S. C. Moran, S. F. Personius, G. Plafker, B. Sherrod, K. Sieh, N. Sitar, and W. K. Wallace (2003). The 2002 Denali fault earthquake, Alaska: a large magnitude, slip-partitioned event. Science 300, 1113-1118.

Eguchi, R. T., J. D. Goltz, C. E. Taylor, S. E. Chang, P. J. Flores, L. A. Johnson, H. A. Seligson, and N. C. Blais (1998). Direct economic losses in the Northridge earthquake: a three-year post-event perspective. Earthquake Spectra 14, no. 2, 245-264.

EQE International Inc. (1995). The Northridge earthquake of January 17, 1994: report of data collection and analysis, Part A: damage and inventory data. Technical Report EQE Project No. 36386.02, EQE International Inc., San Francisco, California, and The Geographic Information Systems Group of the Governor's Office of Emergency Services, Mather, California.

Federal Emergency Management Agency (FEMA) (2000a). Prestandard and Commentary for the Seismic Rehabilitation of Buildings, FEMA-356. Federal Emergency Management Agency, Washington, D.C.

Federal Emergency Management Agency (FEMA) (2000b). Recommended Seismic Design Criteria for New Steel Moment-Frame Buildings, FEMA-350. Federal Emergency Management Agency, Washington, D.C.

Fenves, G. L., and G. Serino (1990). Soil-structure interaction in buildings from earthquake records. Earthquake Spectra 6, no. 4, 641-655.

Graves, R. W. (1998). Three-dimensional finite-difference modeling of the San Andreas fault: Source parameterization and ground-motion levels. Bull. Seism. Soc. Am. 88, no. 4, 881-897.

Graves, R. W. (2005). Broadband simulation for a Mw 6.7 earthquake on the Puente Hills fault. Seism. Res. Lett. 76, 242.

Graves, R. W., and A. Pitarka (2003). Simulation of broadband timehistories combining deterministic and stochastic methodologies, in Proc. of the American Geophysical Union Fall Meeting.

Hall, J. F. (1998). Seismic response of steel frame buildings to near-source ground motions. Earthquake Eng. Struct. Dyn. 27, 1445-1464.

Hall, J. F., T. H. Heaton, M. Halling, and D. Wald (1995). Near-source ground motion and its effects on flexible buildings. Earthquake Spectra 11, no. 4, 569-605.

Hartzell, S., P. Liu, and C. Mendoza (1996). The 1994 Northridge, California, earthquake: investigation of rupture velocity, rise time, and high-frequency radiation. J. Geophys. Res. 101, no. B9, 20,09120,108 .

Haskell, N. A. (1960). Crustal reflection of plane SH waves. J. Geophys. Res. 65, 4147-4150.

Heaton, T., J. Hall, D. Wald, and M. Halling (1995). Response of high-rise and base-isolated buildings to a hypothetical $M_{\mathrm{w}} 7.0$ blind thrust earthquake. Science 267, 206-211.

International Conference of Building Officials (ICBO) (1997). 1997 Uniform Building Code, Vol. 2, International Conference of Building Officials, Whittier, California.

Ji, C., Y. Tan, D. Helmberger, and J. Tromp (2003). Modeling teleseismic $\mathrm{P}$ and SH static offsets for great strike-slip earthquakes, in Proc. of the American Geophysical Union Fall Meeting.

Ji, C., D. J. Wald, and D. V. Helmberger (2002). Source description of the 1999 Hector Mine, California, earthquake, part I: Wavelet domain inversion theory and resolution analysis. Bull. Seism. Soc. Am. 92, no. 4, 1192-1207.

Kohler, M., H. Magistrale, and R. Clayton (2003). Mantle heterogeneities and the SCEC three-dimensional seismic velocity model version 3. Bull. Seism. Soc. Am. 93, 757-774.

Komatitsch, D., Q. Liu, J. Tromp, P. Süss, C. Stidham, and J. H. Shaw
(2004). Simulations of ground motion in the Los Angeles basin based upon the spectral-element method. Bull. Seism. Soc. Am. 94, 187206.

Komatitsch, D., and J. Tromp (1999). Introduction to the spectral-element method for three-dimensional seismic wave propagation. Geophys. J. Int. 139, 806-822.

Krishnan, S. (2003a). FRAME3D—a program for three-dimensional nonlinear time-history analysis of steel buildings: User guide. Technical Report EERL 2003-03, Earthquake Engineering Research Laboratory, California Institute of Technology, Pasadena, California.

Krishnan, S. (2003b). Three-dimensional nonlinear analysis of tall irregular steel buildings subject to strong ground motion. Technical Report EERL 2003-01, Earthquake Engineering Research Laboratory, California Institute of Technology, Pasadena, California.

Krishnan, S., and J. F. Hall (2006a). Modeling steel frame buildings in three dimensions, part I: Panel zone and plastic hinge beam elements. J. Eng. Mech. ASCE 132, no. 4, 345-358.

Krishnan, S., and J. F. Hall (2006b). Modeling steel frame buildings in three dimensions, part II: Elastofiber beam element and examples. $J$. Eng. Mech. ASCE 132, no. 4, 359-374.

Krishnan, S., C. Ji, D. Komatitsch, and J. Tromp (2005). Performance of 18-story steel moment-frame buildings during a large San Andreas earthquake-a Southern California-wide end-to-end simulation. Technical Report EERL 2005-01, Earthquake Engineering Research Laboratory, California Institute of Technology, Pasadena, California.

Liu, Q., J. Polet, D. Komatitsch, and J. Tromp (2004). Spectral-element moment tensor inversions for earthquakes in Southern California. Bull. Seism. Soc. Am. 94, no. 5, 1748-1761.

Magistrale, H., S. Day, R. Clayton, and R. Graves (2000). The SCEC southern California reference three-dimensional seismic velocity model version 2. Bull. Seism. Soc. Am. 90, no. 6B, S65-S76.

Magistrale, H., K. McLaughlin, and S. Day (1996). A geology based 3-D velocity model of the Los Angeles basin sediments. Bull. Seism. Soc. Am. 86, 1161-1166.

Meltzner, A. J., and D. J. Wald (1998). Foreshocks and aftershocks of the great 1857 California earthquake, in Technical Report, U.S. Geol. Surv. Open-File Rept. 98-465.

Olsen, K. B., R. J. Archuleta, and J. R. Matarese (1995). Three-dimensional simulation of a magnitude 7.75 earthquake on the San Andreas fault. Science 270, 1628-1632.

Petak, W. J., and S. Elahi (2000). The Northridge earthquake, USA, and its economic and social impact, in Euro-Conference on Global Change and Catastrophe Risk Management, Earthquake Risks in Europe, IIASA, Laxenburg, Austria.

SAC (1995a). Analytical and field investigations of buildings affected by the Northridge earthquake of January 17, 1994. Part 1. Technical Report SAC 95-04, Part 1, Structural Engineers Association of California, Applied Technology Council, and Consortium of Universities for Research in Earthquake Engineering.

SAC (1995b). Analytical and field investigations of buildings affected by the Northridge earthquake of January 17, 1994. Part 2. Technical Report SAC 95-04, Part 2, Structural Engineers Association of California, Applied Technology Council, and Consortium of Universities for Research in Earthquake Engineering.

SAC (1995c). Surveys and assessments of damage to buildings affected by the Northridge earthquake of January 17, 1994. Technical Report SAC 95-06, Structural Engineers Association of California, Applied Technology Council, and Consortium of Universities for Research in Earthquake Engineering.

Serino, G. (1989). Dynamic soil-structure interaction in building response from earthquake records. Technical Report UCB/SEMM-1989/01, Department of Civil Engineering, University of California, Berkeley, California

Shaw, J. H., and J. Suppe (1996). Earthquake hazards of active blind-thrust faults under the central Los Angeles basin. J. Geophys. Res. 101, no. 34, 8623-8642. 
Sieh, K. E. (1977). A study of late Holocene displacement history along the south-central reach of the San Andreas fault, Ph. D. thesis, Stanford University, California.

Sieh, K. E. (1978a). Pre-historic large earthquakes produced by slip on the San Andreas fault at Pallett creek, California. J. Geophys. Res. 83, 3907-3939.

Sieh, K. E. (1978b). Slip along the San Andreas fault associated with the great 1857 earthquake. Bull. Seism. Soc. Am. 68, no. 5, 1421-1448.

Stewart, J. P., R. B. Seed, and G. L. Fenves (1998). Empirical evaluation of inertial soil-structure interaction effects. Technical Report PEER98/07, Pacific Earthquake Engineering Center, University of California, Berkeley, California.

Suss, M. P., and J. H. Shaw (2003). P-wave seismic velocity structure derived from sonic logs and industry reflection data in the Los Angeles basin. J. Geophys. Res. 108, no. B3, 1-18.

Trifunac, M., T. Hao, and M. Todorovska (2001). Response of a 14-story reinforced concrete structure to nine earthquakes: 61 years of observation in the Hollywood storage building. Technical Report CE 0102, Department of Civil Engineering, University of Southern California, Los Angeles, California.

Trifunac, M., M. Todorovska, and T. Hao (2001). Full-scale experimental studies of soil-structure interaction-a review, in Proc. of the Second
US-Japan Workshop on Soil-Structure Interaction, Tsukuba City, Japan, 52 pp. (CD-ROM).

Wald, D. J., T. H. Heaton, and K. W. Hudnut (1996). A dislocation model of the 1994 Northridge, California, earthquake determined from strong-motion, GPS, and leveling-line data. Bull. Seism. Soc. Am. 86, S49-S70.

Seismological Laboratory

MC 252-21

California Institute of Technology

Pasadena, California 91125

krishnan@caltech.edu

(S.K., C.J., J.T.)

Department of Geophysical Modeling and Imaging CNRS UMR 5212 and Magique3D INRIA Futurs

University of Pau

64013 Pau Cedex, France

(D.K.)

Manuscript received 20 July 2005. 